\title{
Link Path Analysis Komunikasi Gelombang Mikro Topologi Ring Area Kota Padang
}

\section{The Link Path Analysis of Microwave Communications Ring Topology Area of Padang City}

\author{
Nasrul \\ Jurusan Teknik Elektro Politeknik Negeri Padang Kampus Limau Manis Padang 25163 \\ Telp 0751-72590 Fax 0752-72576 Email: nasrulnawi@yahoo.com
}

\begin{abstract}
The development of the telecommunication the rapidly and the increased the need for information , trigger the increasing number of system project communication and discharging radio frequency.This needs to a design and planning ripe to make the existing system can work optimal without any disturbance of discharging frequency two closely ( interference ) .

At the end of this task using software aplication pathloss 5.0 to do design as well as performing calculations link budged in observance of some other factors such as the position of site, the height of the contours of, the condition of propagation, and device used.The end of this duty also using visual basic 2010 to assist in performing calculations link budged.

In the design uses the topology of ring from the area of the Padang city was used in 6 ( six ) link, first bypass to tabing at a distance of link $3,59 \mathrm{~km}$, tabing to minang plaza at a distance of link $1,87 \mathrm{~km}$, minang plaza to hotel pangeran at a distance of link $2,48 \mathrm{~km}$, hotel pangeran to simpang anduriang at a distance link $4,05 \mathrm{~km}$, simpang anduriang tobalai baru at a distance of link 2,31 km and balai baru to bypass at a distance $3,75 \mathrm{~km}$.
\end{abstract}

Keywords : free space loss, link budged, Pathloss 5.0, visual basic 2010

\section{PENDAHULUAN}

Membuat suatu link diperlukan suatu kondisi lintasan propagasi yang bebas hambatan (LOS) dengan penentuan tinggi dan letak antena yang baik di setiap titik serta perhitungan link performansi sistem perangkat sehingga diperoleh kriteria perencanaan yang baik. Untuk menentukan performansi dari antena pemancar hingga antena penerima dibutuhkan perhitungan yang dapat menentukan kemaksimalan kinerja dari sistem komunikasi efective isotropic received power (EIRP), free space loss (FSL), isotropic received level (IRL), received signal lecel (RSL) dan carrier to noise ratio $(C / N)$ dan lain sebagainya.

Perhitungan link budget dan path calculation yang selama ini dilakukan masih melakukan perhitungan secara manual, sehingga akan banyak membutuhkan waktu dan ketelitian yang sangat tinggi, sehingga akan menghasilkan perhitungan yang kurang sempurna.

Dengan menggunakan perangkat lunak (Software) Pathloss 5.0 dan Visual Basic 2010 pekerjaan seorang perencana akan lebih mudah, dan efesien waktu. Alasan itulah yang menjadi daya tarik penulis untuk mengangkatkan judul "Perancangan Link Path dan Analisa Komunikasi Gelombang Mikro Menggunakan Topologi Ring Area Kota Padang".

\section{Tujuan}

Tujuan dari penelitian ini diantaranya adalah untuk:

1. Menghasilkan rancangan komunikasi gelombang mikro pada suatu titik ke titik dalam bentuk topologi ring yang dapat memudahkan pengguna dalam memahami konsep dasar dari sistem komunikasi gelombang mikro. 
2. Memberikan kemudahan kepada penulis dalam melakukan analisa perhitungan link path untuk komunikasi gelombang mikro.

\section{Perumusan Masalah}

Permasalahan yang terjadi pada pembuatan link path analysis untuk komunikasi gelombang mikro area kota padang ini yaitu :

1. Bagaimana merancang link path menggunakan perhitungan secara teori.

2. Bagaimana mensimulasikan serta memuat perhitungan lin kpath untuk komunikasi gelombang mikro berbasis visual basic 2010 dan pathloss 5.0.

\section{Batasan Masalah}

Permasalah yang dibatasi dalam penelitian yaitu pembuatan program simulasi perhitungan link path area kota padang yang meliputi perhitungan EIRP, FSL, IRL, RSL, dan Carrier to Noise serta menampilkan path profile perhitungan dengan bahasa pemrograman Visual Basic 2010 dan pathloss 5.0.

\section{METODOLOGI}

Perancangan sistim e-learning ini dilakukan dalam lima tahap, yaitu :

1. Pendefinisian masalah yang akan dikaji dan dilanjutkan dengan studi literature melalui kajian pustaka mengenai konsep pembelajaran jarak jauh (distance learning).

2. Pengkajian terhadap kebutuhan pengajaran untuk melakukan aktivitas pengajaran melalui web dan analisis terhadap kebutuhan tersebur agar dapat diindefikasikan komponen-komponen dan layanan-layanan yang akan dibangun.

3. Pengkajian terhadap Sistim pendukung untuk mewujudkan Sistim.

\section{Gelombang Mikro (Microwave)}

Gelombang mikro (mikrowave) merupakan pengiriman sinyal radio dengan frekuensi sangat tinggi, yang memanfaatkan udara bebas sebagai media transmisi untuk membawa sinyal informasi pada dua buah relay station yang saling terlihat (tidak terhalang) satu samalain, sehingga tidak adanya interupsi dan informasi dapat diterima dengan jelas.

Komunikasi gelombang mikro menggunakan range frekuensi tinggi dari $1 \mathrm{GHz}$ sampai $300 \mathrm{GHz}$ dengan panjang gelombang 0,3 - $300 \mathrm{~cm}$. Dimana dalam perambatannya menggunakan propagasi Line Of Sight(LOS), lintasan gelombang radio mengikuti garis pandang, artinya antara antena pemancar dan penerima tidak ada penghalang (obstacle). Komunikasi gelombang mikro dapat digunakan dengan jarak 30-50 mil untuk tiap linknya. ${ }^{[2]}$

Komunikasi gelomban gmikro, dapat mengirimkan data lebih besar dibandingkan dengan komunikasi kabel. Karena memanfaatkan media atmosfer bumi sebagai media transmisi. Akan tetapi, pada komunikasi gelombang mikro sangat rentan terhadap cuaca seperti hujan deras maupun badai salju. $^{[2]}$

$$
\text { Aplikasi untuk pelayanan }
$$
komunikasi, antara lain: untuk siaran radio FM, sistem penyiaran televisi (TV), komunikasi bergerak, radar, komunika sisatelit dan penelitian ruang angkasa. ${ }^{[2]}$

\section{Karakteristik Propagasi Gelombang Mikro}

\section{Fading}

Fading adalah naik/turunnya level daya terima sinyal pancaran. Fading disebabkan oleh pengaruh mekanisme propagasi terhadap gelombang radio seperti refleksi (pantulan), refraksi (pembiasan), difraksi (lenturan), atenuasi (peredaman), dan lain-lain.

Faktor-faktor yang mempengaruhi fading adalah:
a. Propagasi multipath
b. Kecepatan pergerakan receiver
c. Kecepatan gerak objek lain 


\section{d. Bandwidth transmisi dari sinyal}

\section{Redaman Propagasi}

Redaman propagasi (Path Loss) adalah besarnya daya yang hilang dalam menempuh jarak tertentu. Besarnya redaman ditentukan oleh kondisi alam seperti tidak adanya halangan antara pemancar dengan penerima. Redaman sangat dipengaruhi oleh jarak antara pemancar dengan penerima dan frekuensi yang digunakan. Adanya pemantulan dari beberapa obyek dan pergerakan mobile station menyebabkan kuat sinyal yang diterima oleh mobile station bervariasi dan sinyal yang diterima tersebut mengalami path loss. Tanpa memperhitungkan kondisi alam dan lokasi dimana pemancar dan penerima berada. ${ }^{[2]}$

\section{Propagasi Garis Pandang (Line Of Sight)}

Propagasi line of sight, disebut dengan propagasi gelombang langsung (direct wave), karena gelombang yang terpancar dari antena pemancar langsung berpropagasi menuju antena penerima dan tidak merambat di atas permukaan tanah.

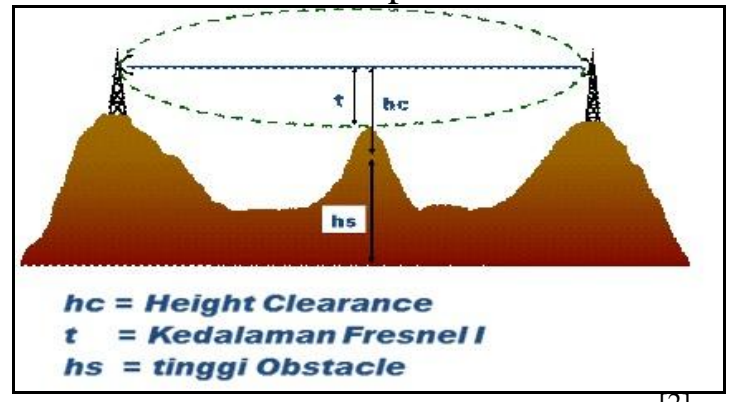

Gambar 1. Propagasi Garis Pandang ${ }^{12}$

\section{Pathloss 5.0}

Pathloss 5.0 merupakan perangkat lunak yang diakui secara international untuk menghitung link budget jalur komunikasi radio maupun UHF. Perangkat ini diterbitkan oleh contracttele comunication engineering dari British Collumbia, Canada yang telah diakui oleh ITU sebagai software untuk menghitung link budget dan merupakan pengembangan dari versi sebelumnya yaitu pathloss 4.0.

Untuk dapat menghitung link budget tersebutdengan menggunakan pathloss 5.0 ada beberapa file penunjang yang harus digunakan. Beberapa file penunjang tersebut adalah base data hujan, informasi perangkat antenna, radio, feeder dan pengkanalan frekuensi. Pathloss5.0 dapat digunakan untuk mengolah informasi topografi daerah, yang dapat diolah dari peta digital dan peta kontur. Peta digital seperti SRTM, DEM, geotiff, Google Earth, Map Info, ESRI file dan lain-lain. Pathloss 5.0 juga telah diberikan data base dari perangkat yang akan di gunakan seperti antena file, radio file, frequensi planning dan lainnya, sehingga lebih memudahkan dalam merancang sebuah komunikasi radio. $^{[1]}$

\section{HASIL}

\section{Perancangan Komunikasi Gelombang Mikro}

Perancangan komunikasi gelombang mikro merupakan proses menentukan posisi pemancar dan penerima yang bagus agar tercapai propagasi garis pandang, serta mengansumsikan daya output yang akan diberikan pada pemancar. Perhitungan link budget gelombang mikro untuk 6 link yang terdiri dari pemancar dan penerima. Parameter yang hitung pada aplikasi rancangan adalah EIRP, FSL, IRL, FSL, $\mathrm{C} / \mathrm{N}$, jarak, dan lossatmosfer. Pada perancangan menggunakan komunikasi 6 hop (link), dimana link yang rancang adalah Bypass-Tabing, Tabing- Minang Plaza, Minang Plaza-Hotel Pangeran, Hotel Pangeran - Simpang Anduriang, Simpang Anduriang-Balaibaru, Balaibaru- Bypass.

\section{Perancangan Link}

Perancangan

komunikasi gelombang mikro area Kota Padang menggunakan topologi ring, komunikasi gelombang mikro yang dirancang dapat terhubung secara line of sight (LOS), oleh karena itu dibutuhkan data-data lokasi site yang ada di daerah Kota Padang, seperti tabel berikut 
Tabel 1. Data Site Area Kota Padang

\begin{tabular}{|l|l|l|}
\hline \multicolumn{1}{|c|}{ Nama Site } & \multicolumn{1}{c|}{ Latitude } & \multicolumn{1}{c|}{ Longitude } \\
\hline Bypass & $-0.872799^{\circ}$ & $100.381590^{\circ}$ \\
\hline $\begin{array}{l}\text { Lubuk } \\
\text { Minturun }\end{array}$ & $-0,84169^{\circ}$ & $100,37836^{\circ}$ \\
\hline Balai Baru & $-0.902640^{\circ}$ & $100.397130^{\circ}$ \\
\hline Pasar Baru & $-0,92708^{\circ}$ & $100,42933^{\circ}$ \\
\hline $\begin{array}{l}\text { Simp. } \\
\text { Anduriang }\end{array}$ & $-0.920768^{\circ}$ & $100.386972^{\circ}$ \\
\hline $\begin{array}{l}\text { Hotel } \\
\text { Pangeran }\end{array}$ & $-0.924056^{\circ}$ & $100.350694^{\circ}$ \\
\hline RRI & $-0,945716^{\circ}$ & $100,362932^{\circ}$ \\
\hline $\begin{array}{l}\text { Minang } \\
\text { Plaza }\end{array}$ & $-0.901806^{\circ}$ & $100.350278^{\circ}$ \\
\hline $\begin{array}{l}\text { Padang } \\
\text { Plaza }\end{array}$ & $-0,902278^{\circ}$ & $100,351167^{\circ}$ \\
\hline Tabing & $-0.885056^{\circ}$ & $100.351667^{\circ}$ \\
\hline $\begin{array}{l}\text { Padang } \\
\text { Centrum }\end{array}$ & $-0,953667^{\circ}$ & $100,362944^{\circ}$ \\
\hline Bandar Buat & $-0,950246^{\circ}$ & $100,421685^{\circ}$ \\
\hline UNAND & $-0,925222^{\circ}$ & $100,440083^{\circ}$ \\
\hline
\end{tabular}

\section{Aplikasi Perancangan}

Aplikasi google earth merupakan sebuah aplikasi mapping online yang menggunakan media satelit Lansat@2014 DigitalGlobe AfriGIS(Pty), Ltd. Dengan menggunakan aplikasi google earth 7.1.4.1529 ini penulis dapat mengambilkan data terrain padasuatu wilayah.Dengancarasebagai berikut:

a. Buka aplikasi google earth 7.1.4.1529,klik icon"Add Placemark"seperti gambar 2.

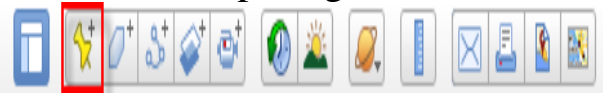

Gambar 2. Icon Add Placemark

b. Masukan nama site dan koordinat pada kolom longitude/latitude site bypass, tabing, minang plaza, hotel pangeran, simpang anduriang, balai baru seperti pada gambar dibawa ini

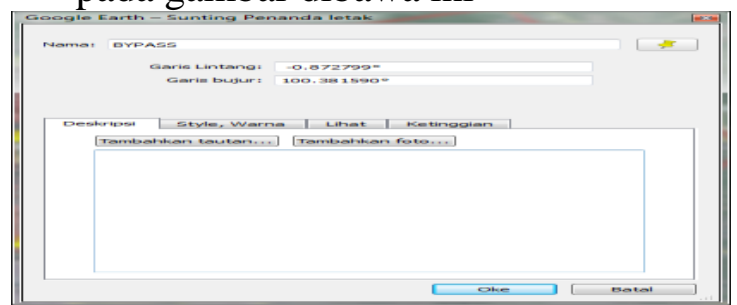

Gambar 3. Placemark Bypass

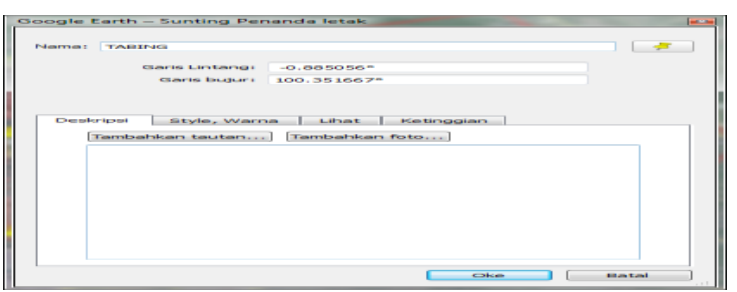

Gambar 4. Placemark Tabing

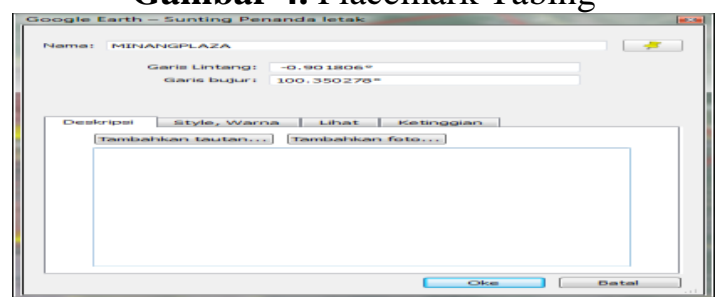

Gambar 5. Placemark Minang Plaza

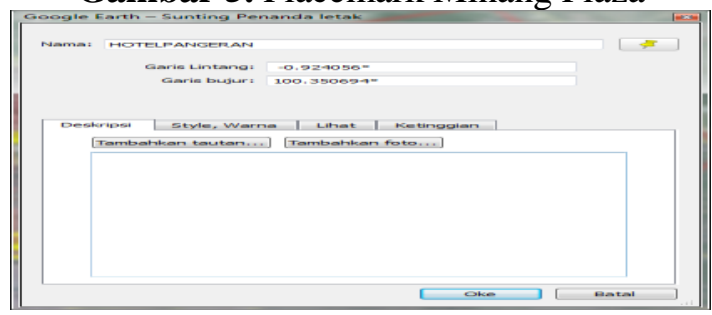

Gambar 6. Placemark Hotel Pangeran

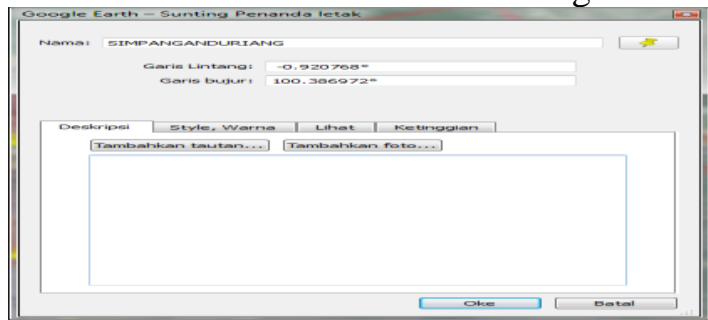

Gambar 7. Placemark Simpang Anduriang

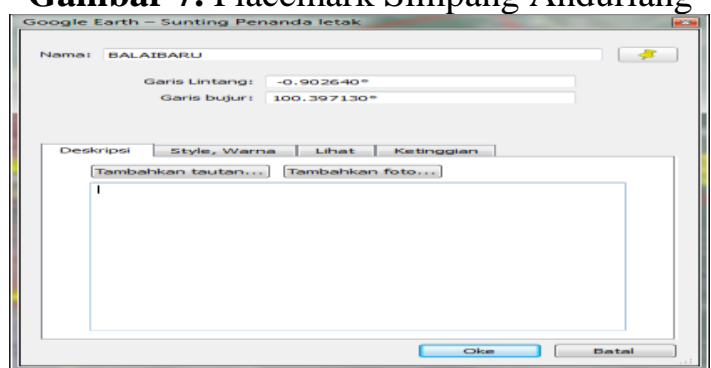

Gambar 8. Placemark Balai Baru

c. Setelah koordinat site dimasukan, maka akan tampil pada google earth koordinat site tersebut sebagai berikut

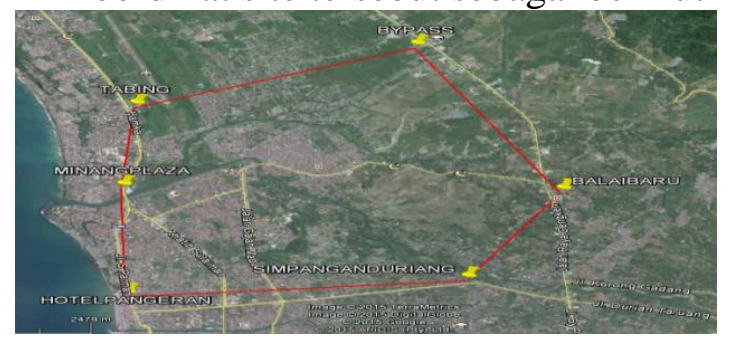

Gambar 9. Posisi koordinat site

d. Setelah itu pilih icon "Penggaris" untuk menghitung jarak dan ketinggian 
wilayah tersebut. Rubah satuannya menjadi kilometer seperti gambar 10 .

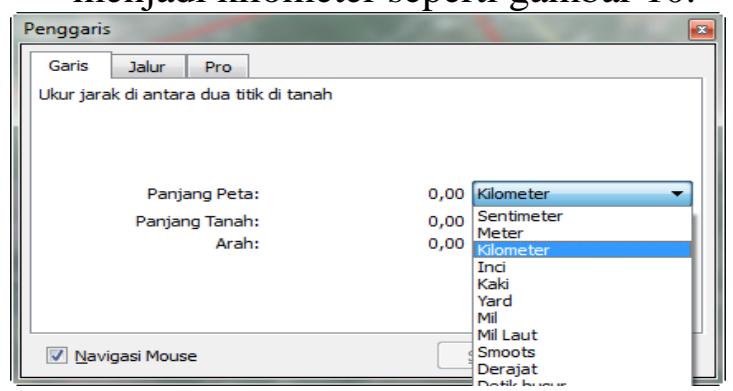

Gambar 10. Jendela penggaris

e. Setelah itu tarik garis dari bypass kearah tabing, lalu klik save pada jendela ruler.Tarik juga dari arah tabing ke arah minang plaza, minang plaza ke hotel pangeran, hotel pangeran ke simpang anduriang, simpang anduriang ke balaibaru, dan balai baru ke bypass.

f. Selanjutnya menampilkan profil ketinggian pada setiap link, untuk pengambilan data terain dengan cara klik kanan pada setiap link dan pilih " Tampilkan Profil Ketinggian”, seperti gambar 11 dibawah ini:

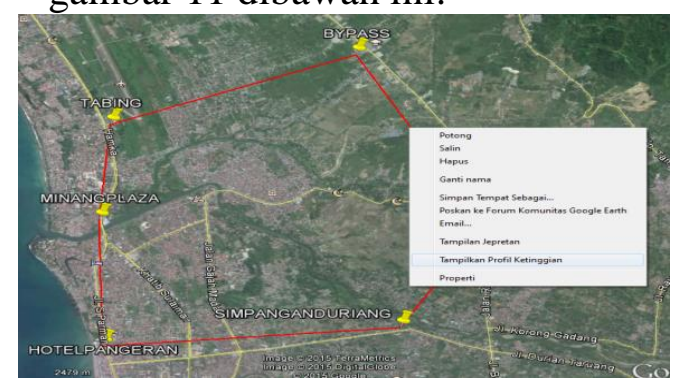

Gambar 11. Tampilan profile ketinggian

g. Pada profile ketinggian akan tampil ketinggian dan jarak antar link.Penulis mengambil data ketinggian setiap jarak $100 \mathrm{~m}$ dan menyesuaikan ketinggian maksimal agar menghasilkan path profile yang sesuai pada software pathloss 5.0

h. Sehingga dapat dihasilkan data terrain dari komunikasi gelombang radio berdasarkan peta digital google earth pada gambar dibawah ini disertai informasi ketinggian masing - masing pada tabel 2.

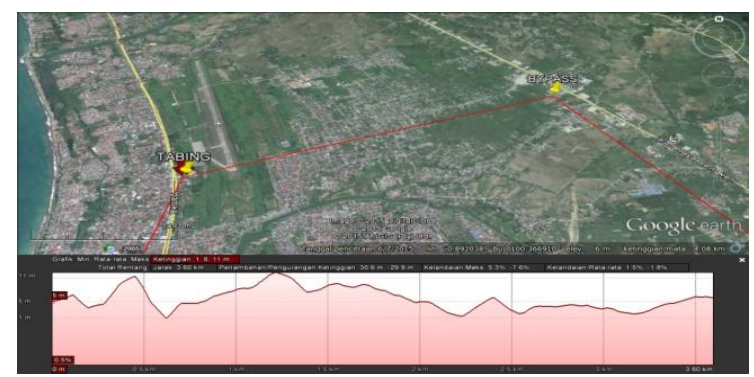

Gambar 12. Profil ketinggian Bypass - Tabing

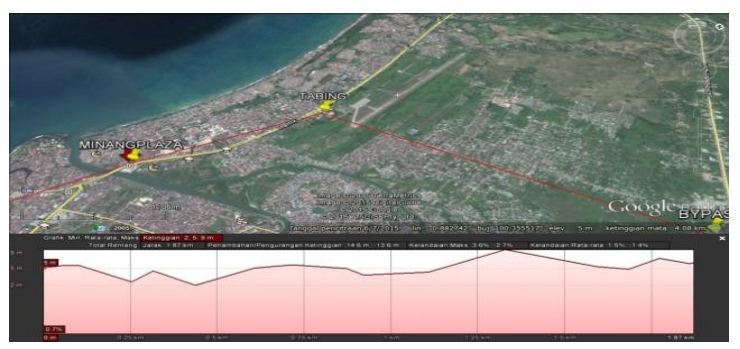

Gambar 13. Profil ketinggian Tabing Minang Plaza

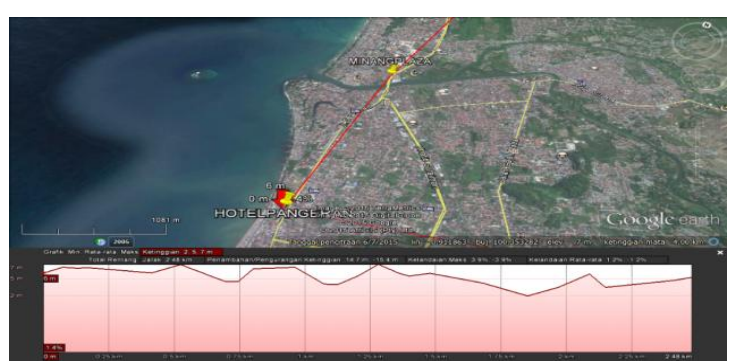

Gambar 14. Profil ketinggian Minang Plaza Hotel Pangeran

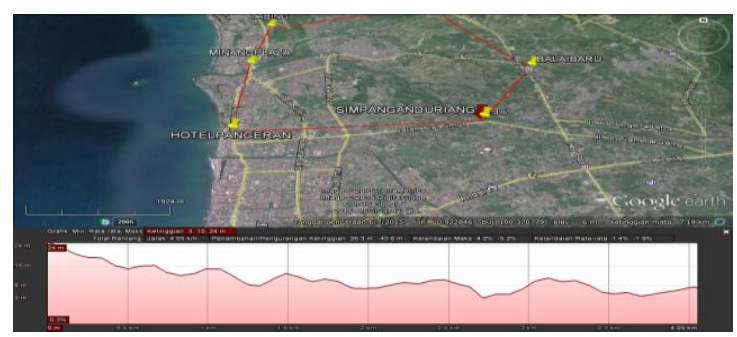

Gambar 15. Profil ketinggian Hotel Pangeran Simpang Anduriang

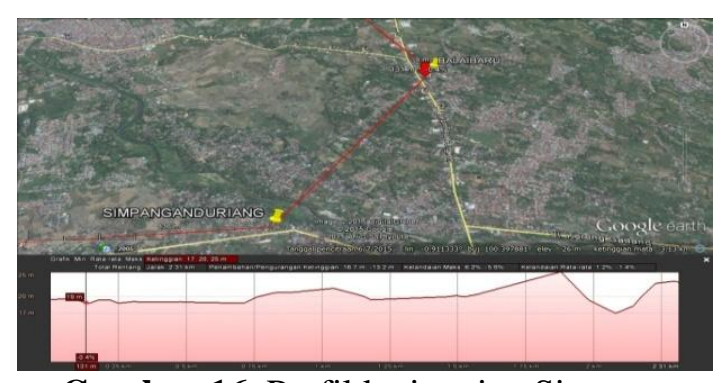

Gambar 16. Profil ketinggian Simpang Andurian - Balaibaru 


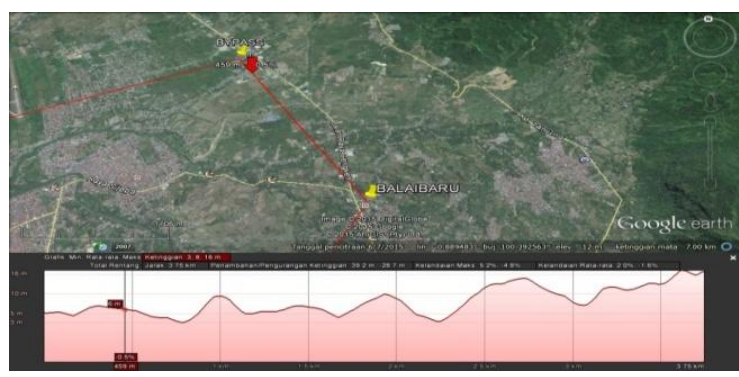

Gambar 17. Profil ketinggian Balaibaru Bypass

Tabel 2. Data Elevation Site

\begin{tabular}{|c|c|c|}
\hline No & Nama Link & $\begin{array}{c}\text { Data Elevation } \\
(\mathrm{m})\end{array}$ \\
\hline 1 & Bypass & 5 \\
\hline & Tabing & 5 \\
\hline 3 & Minang Plaza & 4 \\
\hline 4 & Hotel Pangeran & 7 \\
\hline 5 & $\begin{array}{c}\text { Simpang } \\
\text { Anduriang }\end{array}$ & 24 \\
\hline 6 & Balai Baru & 16 \\
\hline
\end{tabular}

\section{PEMBAHASAN}

Perancangan link path dan analisa komunikasi gelombang mikrowave area kota padang melalui daerah - daerah yang memiliki bangunan yang cukup tinggi, sehingga menarik bagi penulis untuk merancang perhitunganlink pathnya, agar didapatkan propagasi line of sight yang baik. Karena untuk komunikasi gelombang mikro, harus menggunakan metode propagasi line ofsight agar tidak terjadi pemantulan gelombang yangakan mempengaruhi transmisi gelombang mikro. Perancangan komunikasi gelombang mikroarea kota dengan menggunakan topologi ring ini penulis menggunakan 6 site yang terdiri dari site Bypass, Tabing, Minang Plaza, Hotel Pangeran, Simpang Anduriang dan Balai Baru, dimana posisi propagasi merupakan propagasi garis langsung tanpa adanya obstacle (hambatan).

\section{Kondisi Propagasi Garis Pandang}

Kondisi propagasi gelombang mikro pada area kota Padang dengan menggunakan topologi ring dan menggunakan 6 link ini melalui perbukitan rendah sehingga tidak terlalu mempengaruhi jalur propagasi, dengan azimuth antena pemancar Bypass $112,12^{\circ}$ dan penerima pada site Tabing $292,14^{\circ}$ terhadap pemancar. Selanjutnya Tabing terhadap Minang Plaza dengan posisi antena pemancar pada Tabing $355,23^{\circ}$ dan antena penerima Minang Plaza $175,23^{\circ}$ terhadap terhadap pemancar Tabing. Pada pemancar Minang Plaza pposisi antena pemacar pada $181,08^{\circ}$ dan penerima pada Hotel Pangeran $1.08^{\circ}$ terhadap pemancar. Pada pemancar Hotel Pangeran posisi antena pemancar berada pada $275,14^{\circ}$ dan penerima pada Simpang Anduriang berada pada posisi $95,15^{\circ}$ terhadap pemancar. Selanjutnya pada pemancar Simpang Anduriang posisi pemancar berada pada $330,57^{\circ}$ dan penerima Balai Baru pada posisi $150,58^{\circ}$ terhadap pemancar, dan yang terakhir yaitu pada pemancar Balai Baru berada pada posisi $27,66^{\circ}$ dan penerima Bypass pada posisi 207,66 terhadap pemancar, dapat dilihat pada gambar 18.

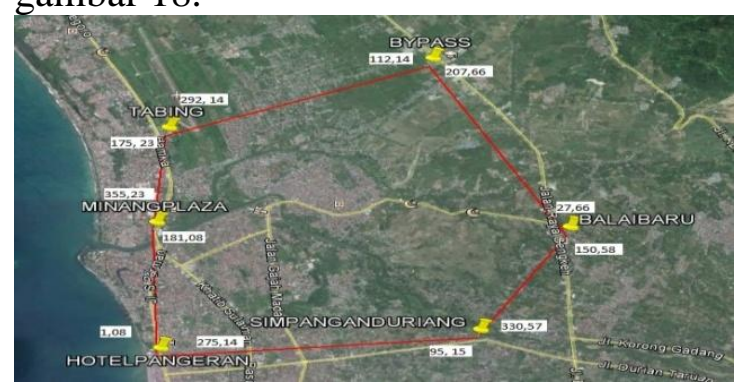

Gambar 18.Azimuth Site

\section{Perancangan Gelombang Mikro}

Setelah melakukan perancangan link serta pengukuran jarak antar link dan input data terrain pada software pathloss 5.0 maka hasilkan data perancangan seperti gambar dibawah ini:

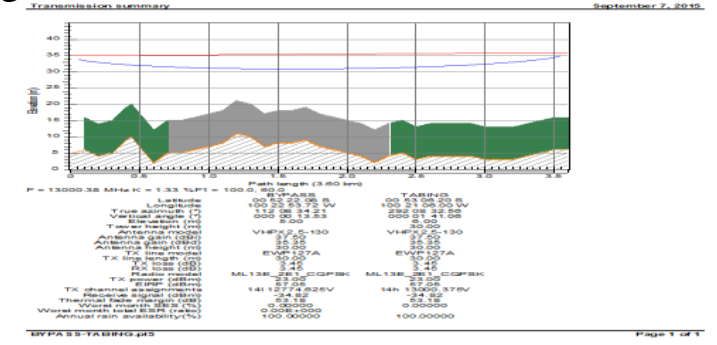

Gambar 19. Transmissi bypas - tabing 


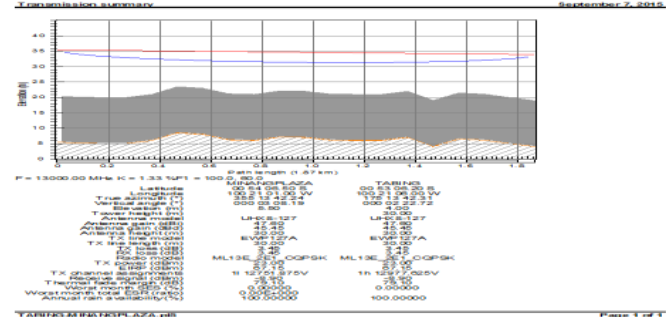

Gambar 20. Transmissi tabing - minang plaza

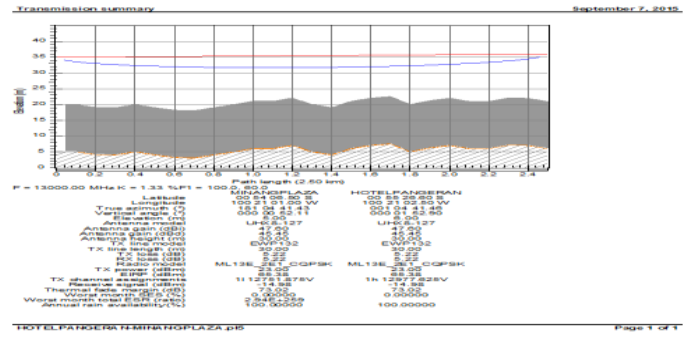

Gambar 21. Transmissi minangplaza - hotel pangeran

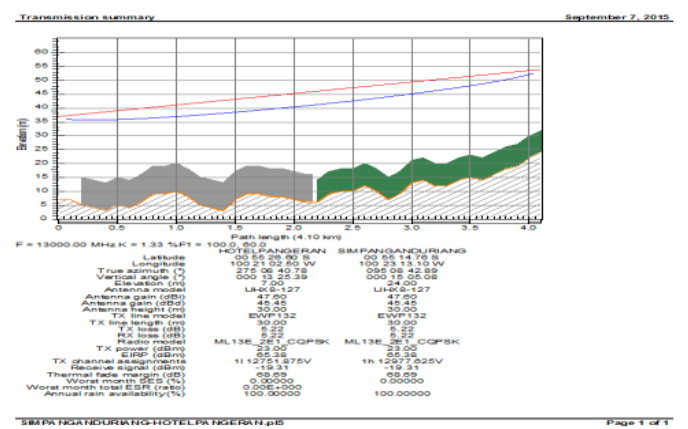

Gambar 22. Transmissi hotel pangeran simp.anduriang

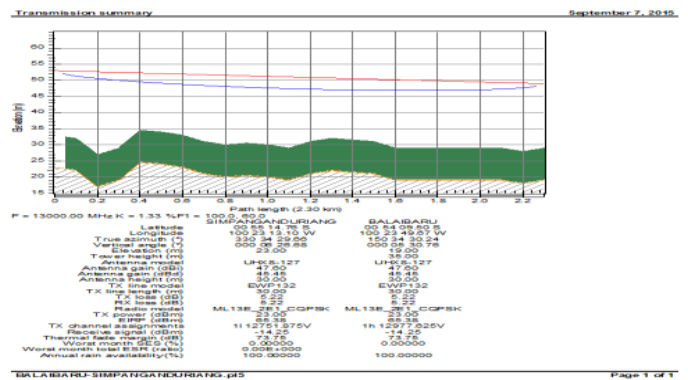

Gambar 23. Transmissi simp.anduriang balaibaru

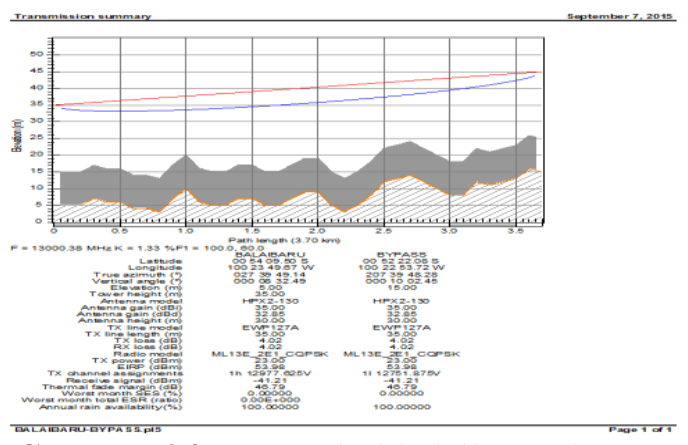

Gambar 24. Transmissi balaibaru - bypass

\section{Jarak Propagasi}

Dengan menggunakan data koordinat site, maka penulis dapat memperhatikan path length (jarak propagasi) antar site. Berdasarkan table 3. koordinat site.

Tabel 3. Koordinat Site

\begin{tabular}{|l|c|c|}
\hline \multicolumn{1}{|c|}{ Site Name } & Longitude & Latitude \\
\hline Bypass & $100.381590^{\circ}$ & $-0.872799^{\circ}$ \\
\hline Tabing & $100.351667^{\circ}$ & $-0.885056^{\circ}$ \\
\hline $\begin{array}{l}\text { Minang } \\
\text { Plaza }\end{array}$ & $100.350278^{\circ}$ & $-0.901806^{\circ}$ \\
\hline $\begin{array}{l}\text { Hotel } \\
\text { Pangeran }\end{array}$ & $100.350694^{\circ}$ & $-0.924056^{\circ}$ \\
\hline $\begin{array}{l}\text { Simpang } \\
\text { Andurian }\end{array}$ & $100.386972^{\circ}$ & $-0.920768^{\circ}$ \\
\hline Balai Baru & $100.397130^{\circ}$ & $-0.902640^{\circ}$ \\
\hline
\end{tabular}

Sehingga dapat dihitung jarak propagasi masing-masing site dengan menggunakan adalah sebagai berikut:

Jarak Lintang:

|Lintang $A-$ Lintang $B \mid * 110.33 \mathrm{Km}$

Jarak Bujur :

$\mid$ Bujur $A-B$ ujur $B \mid * 111.32 \mathrm{Km}$

Sehingga :

Jarak: A dan B :

$$
\sqrt{\text { Jarak Lintang }{ }^{2}+\text { Jarak Bujur }^{2}}
$$

Tabel 4. Jarak Link

\begin{tabular}{|l|c|}
\hline \multicolumn{1}{|c|}{ Nama Link } & $\begin{array}{c}\text { Jarak } \\
\text { (Km) }\end{array}$ \\
\hline Bypass - Tabing & 3,59 \\
\hline Tabing - Minang Plaza & 1,87 \\
\hline Minang Plaza - Hotel Pangeran & 2,48 \\
\hline $\begin{array}{l}\text { Hotel Pangeran - Simp. } \\
\text { Anduriang }\end{array}$ & 4,05 \\
\hline Simp. Anduriang - Balai Baru & 2,31 \\
\hline Balai Baru - Bypass & 3,75 \\
\hline
\end{tabular}

\section{Perhitungan EIRP}

Daya EIRP dipengaruhi oleh daya pancar yang dibangkitkan dari pemancar, dan penguatan antena pemancar. Dan dipengaruhi oleh panjang feeder yang digunakan. Dapat diperhatikan pada perancangan yang di lakukan seperti persamaan dapat diuraikan sebagai berikut :

$$
\mathrm{EIRP}_{\mathrm{dBw}}=\mathrm{Pt}+\mathrm{Lt}+\mathrm{Gx}
$$


Tabel 5. Tabel EIRP

\begin{tabular}{|l|c|}
\hline \multicolumn{1}{|c|}{ Nama Link } & EIRP (dBW) \\
\hline Bypass & 53,000 \\
\hline Tabing & 56,000 \\
\hline Minang Plaza & 48,000 \\
\hline Hotel Pangeran & 53,000 \\
\hline Simpang & 56,000 \\
Anduriang & \\
\hline Balai Baru & 53,000 \\
\hline
\end{tabular}

\section{Perhitungan FSL}

Rugi-rugi ruang hampa yang terjadi pada propagasi microwave dipengaruhi oleh jarak dan frekuensi yang digunakan oleh komunikasi radio. Pada perancangan yang dilakukan, menggunakan frekuensi $13 \mathrm{GHz}$ dengan jarak link1 3,586 Km, jarak link2 6,176 Km, Jarak link3 3,184 Km, jarak link4 8,168 Km, jarak link5 $3.197 \mathrm{Km}$. Berdasarkan frekuensi kerja dan jarak propagasi, maka dapat diasumsikan rugirugiruang bebas pada setiap link menggunakan persamaan, yang dapat diuraikan sehingga dapat diuraikan perancangan sebagai berikut:

$\mathrm{FSL}_{\mathrm{dB}}=32.45+20 \log \mathrm{D}_{\mathrm{km}}+20 \mathrm{Log}$ $\mathrm{F}_{\mathrm{MHz}}[2]$

Tabel 6. Tabel FSL

\begin{tabular}{|l|c|}
\hline \multicolumn{1}{|c|}{ Nama Link } & $\begin{array}{c}\text { FSL } \\
(\mathbf{d B m})\end{array}$ \\
\hline Bypass - Tabing & 124,272 \\
\hline Tabing - Minang Plaza & 124,272 \\
\hline Minang Plaza - Hotel Pangeran & 120,750 \\
\hline $\begin{array}{l}\text { Hotel Pangeran - Simp. } \\
\text { Anduriang }\end{array}$ & 126,770 \\
\hline Simp. Anduriang - Balai Baru & 120,750 \\
\hline Balai Baru - Bypass & 124,272 \\
\hline
\end{tabular}

\section{Perhitungan IRL}

Daya terima pada antena isotropic penerima dipengaruhi

o leh daya pancar pada antena isotropic pemancar dan rugi-rugi ruang hampa berdasarkan frekuensi dan jarak propagasi yang digunakan. Berdasarkan persamaan ini dapatdihitung IRL setiap link sebagai berikut:

$$
\mathrm{IRL}_{\mathrm{dBW}}=\mathrm{EIRP}_{\mathrm{dBW}}+\mathrm{FSL}_{\mathrm{dB}}+\mathrm{Lg}_{\mathrm{dBm}}
$$

Tabel 7. Tabel IRL

\begin{tabular}{|l|c|}
\hline \multicolumn{1}{|c|}{ Nama Link } & \multicolumn{2}{c|}{ IRL (dBW) } \\
\hline Bypass & $-71,000$ \\
\hline Tabing & $-71,000$ \\
\hline Minang Plaza & $-68,000$ \\
\hline Hotel Pangeran & $-72,000$ \\
\hline Simpang Anduriang & $-73,000$ \\
\hline Balai Baru & $-64,000$ \\
\hline
\end{tabular}

\section{Perhitungan RSL}

Daya terima pada penerima dipengaruhi oleh daya terimapada isotropic, gain antenna penerima dan panjang feeder waveguide yang digunakan. Berdasarkan persamaan dibawh ini dapat diuraikan perancangan sebagai berikut:

$$
\begin{gathered}
\mathrm{RSL}_{\mathrm{dBW}}=\mathrm{IRL}+\mathrm{G}_{\mathrm{Rx}}+\mathrm{L}_{\mathrm{Rx}}{ }^{[2]} \\
\mathrm{RSL}_{\mathrm{dBW}}=\mathrm{P}_{\mathrm{Tx}}+\mathrm{L}_{\mathrm{Tx}}+\mathrm{G}_{\mathrm{Tx}}+\mathrm{FSL}+\mathrm{Lg} \\
+\mathrm{G}_{\mathrm{Rx}}+\mathrm{L}_{\mathrm{Rx}}{ }^{[2]}
\end{gathered}
$$

Tabel 8. Tabel RSL

\begin{tabular}{|l|c|}
\hline \multicolumn{1}{|c|}{ Nama Link } & \multicolumn{2}{c|}{ RSL(dBW) } \\
\hline Bypass & $-40,000$ \\
\hline Tabing & $-40,000$ \\
\hline Minang Plaza & $-43,000$ \\
\hline Hotel Pangeran & $-39,000$ \\
\hline Simpang Anduriang & $-48,000$ \\
\hline Balai Baru & $-39,000$ \\
\hline
\end{tabular}

\section{Energy Bit Per Noise}

Energy bit per noise merupakan kemungkinan kesalahan yang terjadi pada komunikasi wireless. Besarnya nilai energy bit per noise ditentukan oleh besarnya nilai tingkat sinyal yang diterima oleh penerima. Nilai perbandingan energy bit per noise dapat diketahui melalui persamaan [2]:

$\square \square / \square 0=\mathrm{RSL}_{\mathrm{dBW}}+204_{\mathrm{dBW}}-10 \mathrm{\square D \square}(\mathrm{BR})-$ $\mathrm{NF}_{\mathrm{dB}}$

Tabel 9. Tabel Eb/No

\begin{tabular}{|l|c|}
\hline \multicolumn{1}{|c|}{ Nama Link } & Eb/No (dB) \\
\hline Bypass & 116.066 \\
\hline Tabing & 165.842 \\
\hline Minang Plaza & 168.543 \\
\hline Hotel Pangeran & 164.867 \\
\hline Simpang Anduriang & 172.179 \\
\hline Balai Baru & 164.649 \\
\hline
\end{tabular}




\section{SIMPULAN}

Dari perancangan komunikasi gelombang mikro yang telah dilaksanakan maka rancangan yang dihasilkan, dapat disimpulkan sebagai berikut:

1. Perancangan menggunakan 6 link site (hop) pada propagasi site area kota padang dengan menggunakan topologi ring serta memperhatikan kondisi kontur daerah menggunakan peta digital.

2. Link yang ditetapkan diantaranya, bypass ke tabing dengan jarak link $3,59 \mathrm{~km}$, tabing ke minang plaza dengan jarak link $1,87 \mathrm{~km}$, minang plaza ke hotel pangeran dengan jarak link 2,48 km, hotel pangeran ke simpang anduring dengan jarak link 4,05 km, simpang anduring ke balai baru dengan jarak link 2,31 km, dan balai baru ke bypass dengan jarak $3,75 \mathrm{~km}$.

\section{SARAN}

Berdasarkan pengalaman penulis selama melakukan penelitian ini, maka penulis dapat memberikan saran :

1. Diperlukannya kerja sama dengan pihak provider atau penyedia layanan telekomunikasi, agar perancangan komunikasi teristerial dapat diimplementasikan dengan baik dan lancar.

2. Adanya konsultasi dengan perusahaan atau pihak-pihak yang mempunyai peranan pada perancangan komunikasi radio teristerial sehingga hasil yang didapatkan sesuai dengan yang dilakukan.

\section{DAFTAR PUSTAKA}

Achmadi. Nur. 2011. Perancangan Jalur Gelombang Mikro

MenggunakanTopologi Ring Di Area Kabupaten Banyumas Dengan Software Pathloss 4. Purwokerto .Akademik Teknik Telekomunikasi Sandhy Putra.

Freeman. Rogel L. 2007. Radio System Design for Telecommunication. Amerika: Wiley - Interscience Publication.

Freeman. Roger L. 1999. Fundamentals of telecomunications. Amerika: John Wiley \& Sons,Inc.

Genubhy. Afira. 2010. Pengukuran Karakteristik Propagasi Kanal VHF Pada Band orbcomm. Surabaya: Institut Teknologi Sepuluh November

Septiahari. Erico. 2010. Saluran Gelombang Mikro. Purwokerto: Akademi Teknik Telekomunikasi Sandhy Putra Purwokerto.

Winch.Robert G. 1998. Telecomunication transmissions ystems.Amerika: McGraw-Hill 